\title{
Food CMS, Integrated Information Sharing System of Food Production, Marketing, and Consumption
}

\author{
Tomoko Kashima $^{*}$, Shimpei Matsumoto ${ }^{\dagger}$, \\ Ken-ichi Fukui ${ }^{*}$, Takashi Hasuike ${ }^{\S}$
}

\begin{abstract}
There are many problems in Japanese agriculture, and the most critical thing among these is a rapid decrease in the working population due to a growing proportion of elderly people. The cause of the aging in the agricultural field would be small incomes due to the low agricultural productivity. To improve the income level, the authors have developed an information sharing system of food production, marketing, and consumption, named food CMS (Contents Management System). Food CMS aims to promote proper management of food resources in the whole food supply chain. The types of users in Food CMS are farmers, customers, and distributors including retailing stores, brokers, and restaurants, so Food CMS has the capability to give benefits appropriate to the types of users. Concretely, Food CMS provides services such as the direct relationship-building between a customer and a producer, sales opportunity with e-commerce, freshness management of foods, and rationalization of the order placement and acceptance work between distributors. Since the integrated database of Food CMS can store all distribution data of foods, the data will contribute to adjusting the supply to demand and reducing the food loss. This paper shows the effort the authors have addressed, especially the functional design of Food CMS, and the performance.
\end{abstract}

Keywords: Farmers Information System, Agribusiness, Farming, Demand Forecasting

\section{Introduction}

Today's Japanese agriculture has had a lot of problems. Many farmers are experiencing a lot of problems nowadays. Farmers are rapidly aging because young people who get an agricultural job are decreasing in number. The percentage of the population engaged in agriculture in Japan has been about $3 \%$ of the workforce since 2002, falling from $26.8 \%$ in 1960. (see Fig. 1 ). The average of the age engaged in agriculture has been about 65years old in 2010, falling from 59years old in 1990.The percentage of GDP (Gross Domestic

\footnotetext{
* Kindai University, Hiroshima, Japan

$\dagger$ Hiroshima Institute of Technology, Hiroshima, Japan

\# Osaka University, Osaka, Japan

$\S$ Waseda University, Tokyo, Japan
} 


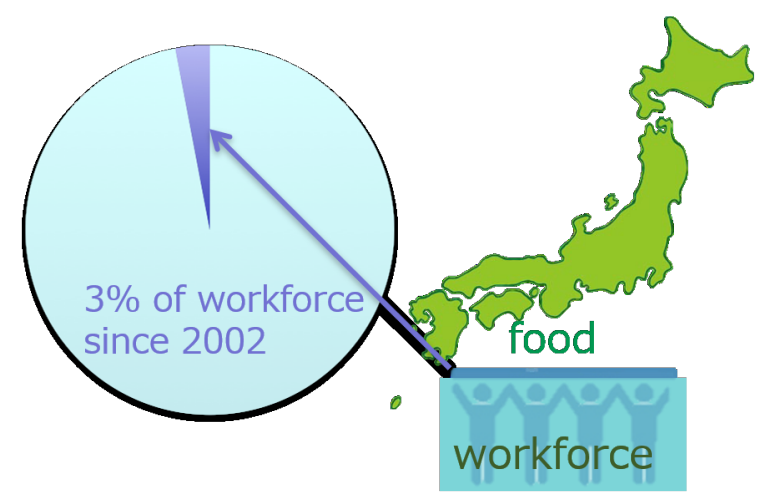

Figure 1: Population engaged in agriculture in Japan

Product) accounted for by agricultural production also dropped from $9 \%$ to less than $1 \%$ during the same period. The importance of agriculture to the Japanese economy has rapidly diminished in Japan with economic growth.

\section{Food CMS}

\subsection{Concept}

Over the years, some studies have been working on the rationalization and improvement of efficiency in the agricultural fields by using IoT (Internet of things) devices such as an instrument (a thermometer, a dew point meter, and a hygrometer), a motion sensor, a camera, and others [1][2]. Similarly, many researchers have recently showed the development results of IoT devices to realize the precision farming. These systems can provide many kinds of valuable information, but they are too expensive. Therefore, a new type of IT blended business model has needed for the agricultural market.

The authors have developed an information sharing system for the farming business named Farmers' Information System (FIS) to manage various farming data and to obtain skillful farmers' knowledge [3]. From the result of trail operation of FIS for a single shop, FIS successed to build the trust relationship between consumers and farmers, and the result would be a firm evidence to guarantee the effectiveness of FIS. The authors previously showed the concept of an integrated information sharing system of food production, marketing, and consumption named Food CMS, which is an expanded system of FIS, to support the distribution of food resources in the whole food supply chain from the production to the consumption [4]. Food CMS will contribute to reducing the food loss, and besides, they will make the improvement of service quality.

In this paper, the authors focus on the capability of information sharing between two points of food distribution, a production point which is a starting point of circulation, and a consumption point which is the last point of food supply chain. We newly implement an information sharing system of food production, distribution, and consumption based on the concept of Food CMS [4]. The functions of Food CMS are designed based on the previous efforts of FIS. To improve manufacturing efficiency of the food industry, the capabilities to collect consumer's voice and to suggest a crop (vegetable) to produce would be essential. The authors believe that these features would be feasible by using the characteristics of 
SNS (Social Networking Service) and e-commerce (EC) system. Food CMS can offer a appropriate function depending on user's role, so each user can get the individual benefits. With Food CMS, it would be possible to build trust relationships between customers and producers which have been heretofore difficult. Additionally, Food CMS would be useful for preserving the freshness of food, expanding the sales opportunities, and improving the sales efficiency of a buyer in the distribution center.

Previously the authors have developed a farming information sharing system named Farmers Information System (FIS) [3] as a new business model for agricultural markets with IT. From around 2000, diet-related issues have been gathering considerable attention from customers in Japan because many customers became sensitive to the safety and security of food called as "accountability" or "traceability". For example, a type of customers strongly desires the information on how and where agricultural products were made, and another type of customers is nervous about the kinds of agricultural chemicals. Under this situation, the authors have aimed to satisfy customer's various needs and to contribute to improving farmer's income with the concept of FIS "Change the domestic agriculture using IT". The benefits on introducing FIS are as follows.

1. Management stability of agriculture.

2. Stable supply of agricultural products.

3. Improvement in the value of agricultural products.

Agricultural products differ substantially from industrial products and daily necessaries because they have the unique factor "nurture", and especially, they are just living things. Therefore, the traceability in the growth process is regarded as the most important added value. Additionally, the preservation of agricultural products is difficult, so it is hard to apply typical production control methods for the management of food. The manufacturing efficiency of agricultural products would be strongly dependent on customer's requests. In order to survive Japanese agriculture under the international competition, creating added value and improving manufacturing efficiency are the key factors. The authors have considered the service that can properly throw individual customer's voice to farmers is effective to achieve the both key factors. The service will enable farmers to produce the proper amount of agricultural products at a suitable time for customers, and the authors have considered that the mechanism of SNS is suitable to realize this type of information sharing service between producers and customers. Until now, there are similar reports with this paper's concept, stressing the necessity of information sharing on food production, consumption, and distribution. For example, Shimizu expected that the coordination between restaurants and farmers' markets will improve farmer's income [5]. In addition, as a report providing the similar view with this paper, Satake's work is worthy of attention [6]. Satake showed the importance of information sharing on the consumer intention, the production schedule, and the logistic flow of agricultural products, which would contribute to reducing the food waste such as the disposal loss due to the overproduction, but also improving the product's value.

As a continuation of above mentioned perspectives, the authors have been developing a new information system named Food CMS for urban agricultural markets to facilitate the transactions and distributions of food. Food CMS specializes in agricultural market, and has blog, EC, and SNS functions. Since Food CMS is a web application package, any Internet accessible devices with web browsing application are available to use. Traditionally, 

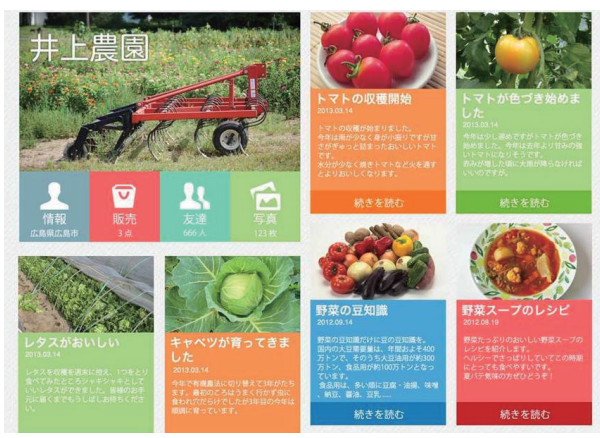

\begin{tabular}{|c|c|c|c|c|c|}
\hline \multicolumn{4}{|c|}{ Farm name and logo } & \multirow{2}{*}{\begin{tabular}{|l}
\multicolumn{1}{|c|}{ News } \\
$\begin{array}{l}\text { Harvest of } \\
\text { tomato }\end{array}$ \\
$\begin{array}{l}\text { Button: } \\
\text { new more text }\end{array}$ \\
\end{tabular}} & \multirow{2}{*}{\begin{tabular}{l}
\multicolumn{1}{c}{ News } \\
Growth of \\
tomato \\
$\begin{array}{l}\text { Button: } \\
\text { new more text }\end{array}$ \\
\end{tabular}} \\
\hline $\begin{array}{l}\text { Basic } \\
\text { Inf. }\end{array}$ & Sales & Friends & | Pictures & & \\
\hline \multicolumn{2}{|c|}{$\begin{array}{l}\text { News } \\
\text { Growth of } \\
\text { lettuce }\end{array}$} & \multicolumn{2}{|c|}{$\begin{array}{l}\text { News } \\
\text { Growth of } \\
\text { cabbage }\end{array}$} & $\begin{array}{c}\text { Information } \\
\text { Tips of } \\
\text { vegetable }\end{array}$ & $\begin{array}{c}\text { Information } \\
\text { Recipe of } \\
\text { vegetable }\end{array}$ \\
\hline \multicolumn{2}{|c|}{$\begin{array}{l}\text { Button: } \\
\text { new more text }\end{array}$} & \multicolumn{2}{|c|}{$\begin{array}{l}\text { Button: } \\
\text { new more text }\end{array}$} & $\begin{array}{l}\text { Button: } \\
\text { new more text }\end{array}$ & $\begin{array}{l}\text { Button: } \\
\text { new more text }\end{array}$ \\
\hline
\end{tabular}

Figure 2: A farmer's website

to develop community-based EC service, open source packages such as EC-Cube, a EC package, and OpenPNE, a SNS package, have been utilized. However, there is no package specialized in the food industry with both SNS and EC features.

\subsection{Basic Functions}

Food CMS consists of two main services, EC service in the front-end page and SNS in the back-end page. The front-end shows a common blog based Web page, and the back-end has the management functions of CMS to construct a website and SNS functions. Food CMS provides two or more default design patterns, but each user can change the design layout of the front-end by editing CSS data from the design edit menu in the back-end. All website visitors including unspecified users not registered as system user can see the website in the front-end, but the contents are limited to unspecified users. That is, each website owner can set different browsing right for each content. The browsing right is not set to the whole page, but to each part of a page. For example, in the case of diary based articles, each article can have unique browsing and sales right.

Along with the real operation of Food CMS, each farmer will upload the articles with pictures such as his/her farming work, growing process, and growing method. Additionally, some kinds of information, what types of chemicals/fertilizers were used to grow the products, or what types of preservatives were added to the products, will be opened. The main objective of Food CMS is to obtain and to share customer's real voice with his/her attribute. These kinds of customer's information would be available for adding values to the products, and as the result, the market will create better quality and better market prices of food. Fig. 2 is the examples of system user's website. These websites show valuable information such as growing process of the products, tips and recipes of vegetables, message and photos, all of which were posted by a farmer, a seller and a sommelier. E-mail is available to add a new article by sending it, so this system is easy to use for novice computer users.

Fig. 3 shows a page of SNS in the back-end. The main objective of SNS is to manage friends, and the service is provided only for the users registered to the system. Most of friends in this system would be business partners such as distributor (shop and restaurant owners), producer, and customer. All friends' activities are shown as the form of time line at the main page of SNS, and the detailed information such as a friend's profile or the details of an activity can be available if a user clicks an interesting feed. The screen shown in Fig. 3 is a farmer's data. This farmer can quickly catch his friend's postings with RSS feeds. Usually, 

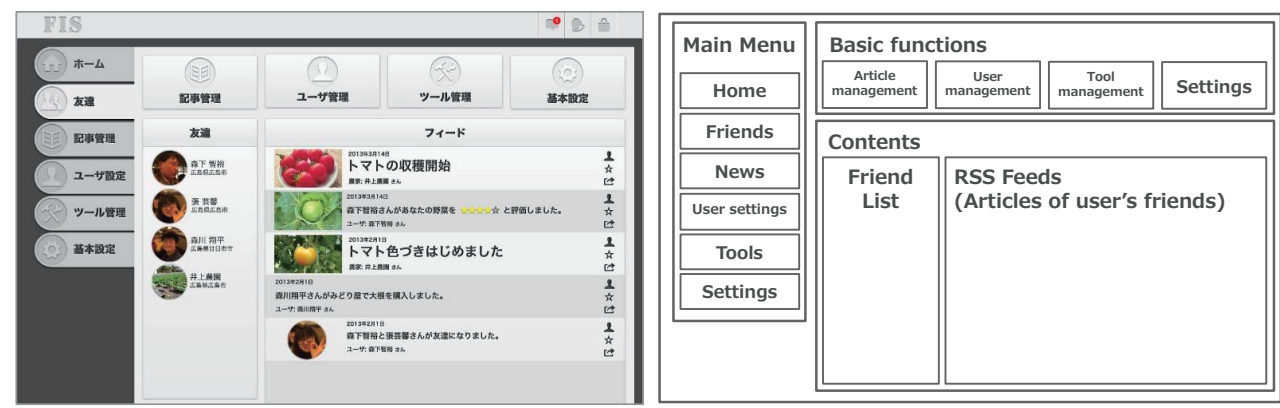

Figure 3: SNS function in the back-end service

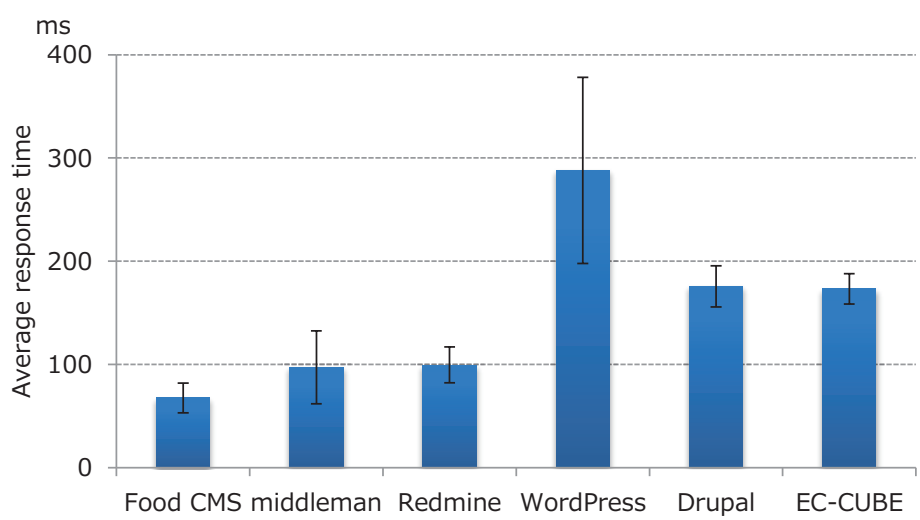

Figure 4: Experimental result

there are many types of postings because the roles of the users are different, and the major roles are farmer, shop owner including restaurant owner, and general customer. Basically, the configuration of screen is same for all types of the users, but the configuration and the number of the left side menu are different depending on the user's role. The main functions of the menu are CMS, EC, SNS, and access log analyzer. Among these, the function of EC is provided only for the users whose role is farmer or shop owner. Each user can set two or more roles because there are possible cases; a farmer sells his products by himself, or a farmer runs a shop and a restaurant while cultivating his/her products.

\section{Implementation and Operation}

\subsection{Effect of Introducing Food CMS}

The authors introduced the prototype of Food CMS to urban farmer's market in Hyogo Prefecture, Japan, and this section shows the effect of the introduction. The prototype had only CMS function for single store, i.e., it had only the front-end service and did not have the back-end service. This paper mainly discloses the results of analysis on the basis of cookies of on-line visitors obtained by the visitor tracking system. Firstly, what type of visitors browsed the shop's website was examined. There are two types of visitors; the one is the group of new visitor whose visit of our domain is first, and the other is returning visitor. The authors got the access log data of visitors just after the trial operation of Food 
CMS. In this operating period, SEO and listing advertising measures had not done. New visitors accounted for approximately $60 \%$ even though the shop manager had not advertised the website. This result shows that Food CMS was viewed online by customers who would want to know the traceability and also desire the information on the safety and security for food. Additionally, the number of returning visitors had been gradually increasing from the introduction of Food CMS. This increase would be the evidence that many returning visitors were interested in the information on the shop's website. The authors expect that Food CMS would contribute to sharing great amounts of information between farmers and customers. Secondly, this paper examined the access source (habitat) of visitors on the basis of the geographic location of IP address. In the access log, the percentage of Hyogo prefecture was high. The result is quite natural because the shop located at Kobe, a city of Hyogo Prefecture. However, about $17 \%$ of whole visitors was from Tokyo (over 500 kilometers away). Food CMS could unveil the existence of potential customers outside the prefecture. Visitors from the outside of the prefecture were mainly browsed information on growing process, and this result would indicate that visitors desired the information of traceability of food. Moreover, not only attracting visitors to the website, the mail orders from Tokyo increased, and the number of sales had become $140 \%$ year-on-year. From these results, the effectiveness of Food CMS is considered to be enough, but the authors should continuously show the further operational results with more trial period than this trial. Also, the authors should examine the effect of SNS function in Food CMS from the result of two or more user's data.

\subsection{Performance}

Food CMS was implemented by using Mac OS 10.9.1 as OS, Ruby 2.1.0-p0 as a development language, RoR 4.0.0 as a web development framework, and MySQL 5.5.29 as a database management system. Gem 2.0.0 was used to manage extension of RoR, and all functions were implemented by using Gem. Active Record 4.0.0 was used to access the database, and paypal-express 0.5.3 was used to implement EC function and online payment with PayPal. Additionally, public_activity 1.4.1 was used to manage user's activity and to show user's feed. These functions were realized by Gem, and Food CMS followed the policy of MVC and RoR. In addition, RSpec 2.14.1, a test tool of objects, was used to realize test driven development, and Cucumber 1.3.10, an operation test tool of front-end, was used.

To verify the usefulness of food CMS, the response time of Food CMS assuming a real operation was compared with the other major CMS(s): WordPress 3.6, Drupal 6.29, PHPbased open source blog package, EC-CUBE 2.13.1, a EC open source package, middleman 3.1.6, Ruby-based open source blog package, and Redmine 2.4.2, Ruby-based open source project management package. A personal computer with $2.5 \mathrm{GHz}$ Intel Core i5 CPU, 8GB $1600 \mathrm{MHz}$ DDR3 RAM, Mac OS 10.9.1 was used to validate these detailed performances. PHP-based CMS(s) were executed by Apache 2.2.24, the most typical web server software, and Ruby-based CMS(s) were executed Webrick 1.3.1, a Ruby library providing web server function respectively. ApacheJMeter 2.11 r1554548 sent 1000 HTTP requests (4 threads and 250 loops) to each CMS, and each response time was measured. The obtained result is shown in Fig. 4, where each bar represents average response time, and the error bar represents standard deviation. In Fig. 4 left three CMS(s) are Ruby-based software, and right CMS(s) are PHP-based software. All of the average response times of Ruby-based CMS(s) including Food CMS were better than the PHP-based CMS(s). From the result of 
Welch's t test between Ruby and PHP with 3000 response times, Ruby was significantly shorter than PHP. The response time of Food CMS was the best among these CMS(s), so the usefulness of Food CMS is considered to be enough.

\section{Discussion}

The effort of this paper provided an information publishing mean to disclose the content that only farmers can have, and also created a value-creation opportunity. For example, Food CMS can continuously distribute various kinds of information: pesticides used for agricultural crops, growth situation of well-selected agricultural crops, a way of eating deliciously, and preservation method of an ingredient, all of which strongly relate to the safety of agricultural crops. In the present version of Food CMS, implementing the core functions has been completed, but expanding capability of Food CMS will be continuously addressed by the feedback from farmer's opinion mainly given through the real operation. Finally, the authors aim to publish Food CMS as an open source package to facilitate integrative information sharing available for all kinds of persons in food production, marketing, and consumption.

In general, as customers and farmers have required different types of information on agricultural products from food markets, Food CMS can provide each user's desired information. In this condition, Food CMS will be utilized by two different types of users; the one is users who will actively write to Food CMS, and the other is read-only. The most of former users are assumed to be mainly agricultural producers. Most of their postings are to disclose the production schedule and the growth records of products, which will contribute to providing full traceability of food. The latter users are mainly visitors to restaurants. They will not post actively, but want to see the photos published on the system from farmers. In fact, restaurant's guests may require the exact information of agricultural products or their safety. Similarly, a farmer may want to show the information about his/her products. Their communication has been usually difficult with only the usual system of food distribution. Food CMS can assist the interaction between both types of users. If a farmer considers customer's demand into his/her farming schedule properly, he/she will have a possibility to gain sales opportunity of his/her products. Each farmer should be aware of customer's specific demand when he/she really wants to improve his/her income. This type of information sharing will lead to avoiding the usual Japanese agricultural issue that agricultural products are sold at a very low price. Food CMS would create an awareness of food marketing to each farmer because grasping actual customer demand has a possibility to improve product's value. As the result of growing farmer's consciousness for his/her products, Food CMS will contribute to adjusting farming schedule, on-demand production, i.e., a farmer will grow his/her products at the time just customers want.

\section{Related Works}

\subsection{Related Commercial Services}

Similar services with Food CMS have been already in operation. This paper shows 5 services as the examples of agricultural informatization; Telefarm, Radishbo-ya, Agrisaurus, Farmers WEB, and Good eggs. Telefarm and Radishbo-ya are services of Japan, and the others are U.S. services. The business target of these services is B to B or B to C commerce. 
As the added value for farmers, this paper gives 6 features; Social networking function, analyzer, game and local contribution, traceability, safety and security, knowledge sharing, local production for local consumption, and insentive for customers.

Telefarm ${ }^{1}$ has provided an Internet-based remote cultivation service to grow organic vegetables through the operation from a home PC, a portable digital device including a smartphone and a personal digital assistant, or a game terminal. The service of Telefarm is $\mathrm{B}$ to $\mathrm{C}$ commerce, and its added values are social networking function, gamification, traceability, and local revitalization. Web system for remote cultivation of agricultural crops links to a real farm, and the real farm follows the directions, such as the selection of plants, a cultivation method, and the use of materials, given by the online user. Additionally, harvested organic vegetables are delivered to each user's door. The aim of Telefarm is to contribute to activating rural areas and food safety. Radish-boya ${ }^{2}$, a group company of NTT DoCoMo, Japan's largest telecommunications company, is an online supermarket to provide a regular home delivery service, and have sold organic and low-pesticide vegetables and additive-free food. The service of Radishbo-ya is B to B and B to C commerce, and its added value is the provision of safety and security for food. Taking advantages of major company, the number of articles and information is abundant, and besides, the reliability of the information is also high. Farmscape ${ }^{3}$ is a support service in order to enjoy home garden readily by common people. The core service of Farmscape is knowledge sharing. When a user applies for the service, a planter to grow vegetables is delivered, and farmers with abundant experience and know-how will regularly come for helping home garden. Farmigo ${ }^{4}$ is an online farmer's market, and connects the farms directly with the customers. The service of Farmigo is B to B and B to C commerce, and its added value are local production for local consumption and the provision of traceability. Farmigo allows customers to get vegetables just after these harvests, so that it is fresher than anything they can buy at a supermarket. Farmers have full accountability where their food is coming from. One of the main reason drawing people's attention to Farmigo is that the market in Farmigo has sold only safe local food, and have not dealt with additive and genetically modified food. Good Eggs $^{5}$ is an online interactive supermarket, which provides locally grown products that will be delivered to the user's door. The mission of Good Eggs is to offer fresh, nutritious food and vegetables as well as local meat, dairy and eggs that come from naturally grown animals. The service of Good Eggs is B to B and B to C commerce, and its added value are local production for local consumption and safety and security, so the business type of Good Eggs is similar with Radishbo-ya.

\subsection{Related Studies}

Previous studies on agricultural promotion with computerization have attained various kinds of developments such as support methods of traceability for branding agricultural products, optimizing techniques of farming harvests for improving productivity, and farming expert's knowledge acquisition methods by utilizing the sensing technology and the big data of agricultural works. For example, Takatsu et al. focused on adopting IT to the agricultural field as a solution to the shortage of successors. Takatsu et al. also considered some measures

\footnotetext{
${ }^{1}$ Telefarm, http://www.telefarm.net/

${ }^{2}$ Radishbo-ya, http://www.radishbo-ya.co.jp/shop/

${ }^{3}$ Farmscape, http://farmscapegardens.com/

${ }^{4}$ Farmigo, https://www.farmigo.com/

${ }^{5}$ Good Eggs, https://www.goodeggs.com/sfbay/home
} 
for solving succession problem of agriculture, vitalizing agricultural business, and improving farmer's income by predicting the harvest time and the amount of yield [7]. Toward the practical use of Takatsu's concept, using a cloud service is thought to be essential because it is necessary to reduce the cost. Similarly, Saito et al. reported the effectiveness of information system for agriculture [8]. Saito et al. showed that ensuring traceability and accountability of food would have a potential to contribute to the branding of agricultural products. On the other hand, Saito et al. pointed out that a distributor in agriculture-commerceindustry cooperation must not be limited by a regional farmers' market, a roadside station, and a department store. To open the agricultural market for various distributors, some kind of mechanism to comprehensively manage distribution data would be essential, and Food CMS is considered to be a real form of the awareness of this finding.

Since safety and security of food and environment-maintaining agriculture have attracted a lot of attention from Japanese society, many technologies have been actively developing. However, most of these efforts were limited to the area of a certain closed problem. Therefore, each effort has had difficulties to progress and spread the whole society in Japan. Hayashi et al. pointed out that there have been many cases where the reduction of a particular risk led to the increase of another risk, or the original advantages/benefits significantly lost by the risk mitigation [9]. Hayashi et al. also cited that improving the efficiency of entire food system is technically difficult when including various types of factors such as the environmental factor and the food productive factor, and besides, the lack of means to adequately evaluate a developed technology would be the primary cause that many research efforts have not been accepted into the society. Nanseki et al. proposed a next-generation food system for ensuring the reliable supply of safety food at low-cost [10]. Nanseki et al. stated that various kinds of risks on not only food itself, but also agricultural productive activities, resources and environment including farmland, soil, and water, as a basis for the productive activities, must be inclusively considered. A some technology for rationalizing entire food system including such various factors must be developed from the viewpoint of overall optimization in food distribution. Of course, the technology should consider the fact that agriculture has both positive and negative sides against the natural environment [11][12]. Our motivation for developing integrated information sharing system of food distribution follows the above mentioned knowledge.

\section{Conclusion}

This paper showed the concept of Food CMS, integrated information sharing system of food production, marketing, and consumption, as a solution to the present Japanese agricultural fields, and the result of implementation of Food CMS so far. The structure to directly connect stakeholders in agricultural businesses, mainly farmers, customers and stores, were developed by Food CMS. On the other hand, the developed system in this paper was a simple prototype, so the technical structure of Food CMS will be examined to cooperate further with the stabilization of agricultural management and the support mechanism for the stable supply of agricultural products. The considerable merit with Food CMS is to ensure traceability of food for customers, and it would lead to improving the service quality. The collected data of Food CMS will support to collect a new kind of knowledge, so the authors will report the operational result certifying this point in future works. 


\section{Acknowledgement}

The authors are very grateful to member of Institute of Agricultural Products Distribution Research, for their valuable cooperation in experiments. This work was partly supported by Japan Society for the Promotion of Science, Grant-in-Aid for Young Scientists(B), No.25750007 and 26th Artificial intelligence research promotion foundation.

\section{References}

[1] T. Togami, R. Ito, A. Hashimoto and T. Kameoka, Agro-Environmental Monitoring Using A Wireless Sensor Network to Support Production of High Quality Mandarin Oranges, Japanese Society of Agricultural Informatics, Vol.20, No.3, pp.110-121(2011).

[2] K. Kamimura, The management problem of Japanese agriculture, Journa of Management consulting, Vol.55, No.9, pp.28-31(2008).

[3] T. Kashima, S. Matsumoto and T. Matsutomi, Effects of Sharing Farmers' Information using Content Management System, Online Communities and Social Computing, (Eds: A. Ozok, P. Zaphiris), pp.296-303 (2013).

[4] T. Kashima, S. Matsumoto, A Content Management System for Food Industry, Proc. of The Second Asian Conference on Information Systems, ACIS 2013, pp.231-238 (2013).

[5] Ayumi Shimizu, Tomohiro Uchiyama, The Viability of Farmers Markets' Development by Partnering with Local Restaurants, Agri Economics of Food, Vol.58, No.2, pp.12-19, 2012, In Japanese.

[6] Yuichi Satake, Tomihiro Yamazaki, Using food and agriculture cloud to improve value of food chain, FUJITSU, Vol.62, No.3, pp.262-268, 2011, In Japanese.

[7] Shiro Takatsudo, Hiromi Murakami and Takeshi Oba, Application of M2M service platform for agriculture ICT, Technical Report of NEC, Vol.64, No.4, pp.31-34, 2011, In Japanese.

[8] Osamu Saito, Fundamental Problems and Strategy about Food-agriculture Alliancebased Food System, Agriculture \& Horticulture, Vol.84, No.8, pp.787-793, 2009, In Japanese.

[9] Kiyosada Hayashi, Trade-off in Agricultural Production System, Society for Soil and Water, Vol.27, pp.44-50, 2010, In Japanese.

[10] Teruaki Nanseki, Food Safety and Information Technology, Society of Agricultural Informatics, Vol.17, No.4, pp.161-170, 2008, In Japanese.

[11] Stolze, M., Piorr, A., Haring, A. and Dabbert, S.: The Environmental Impacts of Organic Farming in Europe, Organic Farming in Europe, Economics and Policy, Vol.6, 2000 ,

[12] Shortle, J. and Abler, D.: Agriculture and the environment, Handbook of environmental and resource economics 2002 (J. Bergh Eds.), pp.159-176, 2002. 